\title{
Assessing the effectiveness of an ergonomics intervention program with a participatory approach: ergonomics settlement in an Iranian steel industry
}

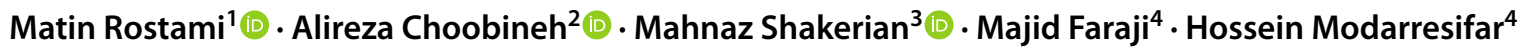

Received: 6 July 2021 / Accepted: 9 October 2021 / Published online: 30 November 2021

(๖) The Author(s), under exclusive licence to Springer-Verlag GmbH Germany, part of Springer Nature 2021

\begin{abstract}
Purpose Work-related musculoskeletal disorders (WMSDs) are common occupational problems affecting the health and productivity of workers worldwide. Ergonomic intervention programs (EIPs) can play an effective role in preventing these disorders in the workplace. Assessing the effectiveness of an EIP is a challenge faced by both industries and researchers. This study was aimed at assessing the effectiveness of an EIP on human resources productivity (HRP), musculoskeletal disorders (MSDs), general health and occupational fatigue in a steel industry.

Methods This study was conducted in a steel industry in Isfahan, Iran, between 2018 and 2021. To assess the effectiveness of the EIP with a participatory approach, training and redesign of workstations, the criteria of HRP, MSDs, general health and occupational fatigue were investigated before and after the intervention, using HRP Questionnaire, Nordic musculoskeletal questionnaire (NMQ), 28-item General Health Questionnaire (28-GHQ), Swedish Occupational Fatigue Inventory (SOFI-20) and Occupational Fatigue/Exhaustion Recovery (OFER-15) Questionnaire, as data collection tools, respectively. Results The implementation of EIP in the studied industry significantly led to an increase in $\operatorname{HRP}(p<0.05)$. The prevalence of MSDs decreased significantly in most regions of the body after the interventions $(p<0.001)$. In addition, the program significantly improved general health $(p<0.001)$ and reduced occupational fatigue among employees $(p<0.001)$.

Conclusions The implementation of EIP was significantly effective in working conditions improvement. Therefore, implementing EIP with participatory approach, workforce training, as well as redesigning of workstations are recommended in industries.
\end{abstract}

Keywords Participatory ergonomics intervention program $\cdot$ Human resources productivity $\cdot$ Musculoskeletal disorders · General health $\cdot$ Occupational fatigue

Matin Rostami and Alireza Choobineh contributed equally to this work and should be considered co-first authors.

Mahnaz Shakerian

Shakerian.mahnaz@gmail.com

1 Department of Ergonomics, School of Health, Shiraz University of Medical Sciences, Shiraz, Iran

2 Research Center for Health Sciences, Institute of Health, Shiraz University of Medical Sciences, Shiraz, Iran

3 Department of Occupational Health Engineering, School of Health, Isfahan University of Medical Sciences, Isfahan, Iran

4 Mobarakeh Steel Company, Isfahan, Iran

\section{Introduction}

Work-related musculoskeletal disorders (WMSDS) have been identified as the fourth leading cause of health costs worldwide (Hallman et al. 2019) and are still considered as one of the most important predicaments prevailed both industrially developed and developing countries (Choobineh et al. 2013a; Shahnavaz 1987). Musculoskeletal disorders (MSDs) mostly commence with feelings of fatigue, discomfort or pain in the musculoskeletal system (Pope-Ford and Pope-Ozimba 2020) and, if long lasting, can adversely affect general health and well-being (Oakman et al. 2017), performance and productivity (Onishi et al. 2014), and the quality of life, all of which may be ultimately augmented by psychological problems, such as depression and job stress (Bosch et al. 2018). A wide range of workplace MSDs risk 
factors (Haynes and Williams 2008; Kujerdi et al. 2021; Tajvar et al. 2021) impact not only employees but industry and society as well (Choobineh et al. 2016). Based on the literature, WMSDs are still rising gradually in developing countries, including Iran (Hosseini et al. 2019). Numerous factors, such as ergonomic risk factors including poor workstation design, prolonged static sitting and manual material handling, etc. are well-known risk factors contributing to WMSDs (Bernardes et al. 2021; Hayati et al. 2021; Lawson et al. 2021; Ziaei et al. 2021).

Although it seems difficult to obtain accurate and reliable statistics related to the prevalence of WMSDs in Iran, in recent decades, the high prevalence of these disorders accompanied with the necessity of controlling their risk factors is highlighted in some previous studies (Tajvar et al. 2021). For instance, in a study conducted on waste collectors in Iran, $92.5 \%$ of individuals reported symptoms of MSDs in at least one of their body regions (Ziaei et al. 2018). Besides, the results of another study on Iranian farmers showed a high prevalence of MSDs in the lumbar region (59.3\%), knees (36.9\%) and back (36.6\%) (Momeni et al. 2020). In addition, Choobineh et al. in his study on Iranian settings reported that the prevalence of MSDs among workers could reach up to $87.1 \%$ (Choobineh et al. 2009). In addition, based on the findings of another study undertaken by Choobineh et al. 90.3\% of Iranian healthcare workers reported MSDs (Choobineh et al. 2016).

According to the European Institute for Occupational Safety and Health in 2020, the occurrence of MSDs may increase anxiety, sleep problems and general fatigue among workers (Tompa et al. 2021) and trigger some psycho-social risk factors and their adverse effects in the workplace inducing decreased workers' well-being in general (Daneshmandi et al. 2019). On the other hand, according to the study by Daneshmandi et al. occupational fatigue is not only considered as a consequence of MSDs but can increase the possibility of accident occurrences and sick leave in the workplace as well (Daneshmandi et al. 2017). Decreased alertness as a result of occupational fatigue can reduce safety level caused by failure in decision-making ability, distraction from intricate tasks and loss of vigilance in critical situations (Dohrmann and Leppin 2017; Yancheshmeh et al. 2020). Therefore, the prevention of WMSDs in the workplace is a crucial issue remarkably affect health, safety and productivity of employees (Daneshmandi et al. 2017).

Risk factors related with the WMSDs occurrences have been indicated to be mainly of biomechanically stressful innate, such as awkward postures, high force exertion and repetitive tasks (Emmatty and Panicker 2019; Jacobo-Galicia et al. 2021; Neshastegar et al. 2019). However, psychosocial and organizational risk factors, including lack of an appropriate work-rest cycle and recovery time, lack of an effective work program to prevent occupational injuries as well as the individuals' burnout and improper working conditions, i.e., poor lighting and vibration have also shown among risk factors increasing WMSDs and disability in developing countries (Choobineh et al. 2013a; Hosseini et al. 2019). In a study, for instance, Ervast et al. showed that prolonged exposure (8-10 years) to heavy physical activity in the workplace could increase both MSDs and disability pensions (Ervasti et al. 2019).

Steel industry is known as a high-risk industry for developing WMSDs due to the existence of various occupational risk factors, including awkward postures, repetitive tasks, manual material handling, etc. (Choobineh et al. 2011, 2013b). However, a better understanding of ergonomic principles and their applications in the workplace can have a significant impact on both employees' health and organization productivity (Bazazan et al. 2019). Many studies have confirmed a decreasing trend in prevalence of WMSDs through implementing ergonomic intervention programs (EIPs) including workstation redesign, training programs and the foundation of participatory ergonomics in the workplace (Motamedzade et al. 2003; Bernardes et al. 2021). Having implemented an EIP in a steel industry, Choobineh et al. assigned the need for a multi-purpose EIP to improve the impact of interventions on workers' health and productivity (Choobineh et al. 2012).

Many studies have emphasized on the utilization of postural and workstation intervention programs, some of which have been able to reduce the occurrence and prevalence of MSDs symptoms (Amick III et al. 2003). Some of these interventions, however, have not shown any significant effect (Cook and Burgess-Limerick 2004; Gerr et al. 2005). Literature shows that most of the participatory ergonomic intervention methods from passive training techniques (e.g., lecturing, delivering educational films, and pamphlet-making) to performance-based techniques (e.g., workstation redesign by encouraging workers to participate in the process of identifying risk factors and finding solutions) play an important role in decreasing WMSDs occurrences in the workplace (Wilson and Haines 1998; Cole et al. 2005; Burke et al. 2006). For example, Bernardes et al. developed a low-tech and low-cost solution that successfully reduced workers' exposure to WMSD risk factors and found participatory ergonomic interventions as a feasible and effective approach to decrease the exposure to work-related risk factors for WMSDs in industrially developing countries (Bernardes et al. 2021).

Nevertheless, there are challenges in implementing participatory ergonomic programs, such as insufficient intervention time (Van Eerd et al. 2010). Although overcoming these challenges seems possible, the extent to which they affect the success of EIPs is still far-fetched (Van Eerd et al. 2016). Besides, there is little known about the effectiveness of such ergonomic interventions on the occurrence of WMSDs on 
industrial workplaces. In addition, literature shows limited knowledge on the fact that how an effective ergonomic intervention may, directly or indirectly, affect employees' health and performance in the workplace in respect of general health, productivity, fatigue, MSDs, etc. (Rasmussen et al. 2018). Therefore, according to the aforementioned explanations, this study was conducted to assess the effectiveness of an EIP with a participatory approach among employees of an Iranian steel industry.

\section{Materials and methods}

This study aimed at assessing the effectiveness of a participatory EIP in a steel industry, conducted in two phases between 2018 and 2021, in Iran. The industry was the largest steel maker of MENA (Middle East and Northern Africa) region, and one of the largest industrial complexes operating in Iran (more than 14,000 personnel). It encompassed manufacturing units and 6 technical and maintenance units as well as office departments, of which eight main units were selected to enter the study based on the industry occupational health department suggestion. The selected units included "general service and welfare", "central workshop", "steel production", "cold rolling", "transportation", "iron production", "human resources (HR) education and development", and "information technology (IT)". This study was conducted over 2 years: 6 months to hold training sessions and fulfilling the questionnaires before the EIP, 18 months to implement EIP measures, and 3 months to collect and analyze the questionnaires after the EIP. To make the study methodology more clarified, a brief description of the EIP implementation steps is also explained below. It should be noted that the explicit methodology explanation and findings of the first phase of the project including list of ergonomic interventions have already been presented elsewhere (Choobineh et al. 2012).

\section{Phase 1: design and implementation of ergonomic intervention program}

In the first step, the research team gave an overview of the entire program including the perspective and the objectives of the project to the management team of the industry. Then, to pave the way for localizing ergonomics principles over the whole industry a steering committee was formed consisting of ergonomics team, i.e., research team members, senior managers of the industry, and the heads and experts of HSE departments of targeted industrial units.

Then, prior to forming action groups, all necessary and practical contexts in ergonomics were taught to the steering committee members during regular training workshops through an organized and systematic schedule. The initial plot considered for ergonomics training was developed based on a cascade model (Jacobs 2002). Then, four 2 day workshops were attended by the steering committee members and the essential contexts of ergonomics, such as physical ergonomics, manual material handling, biodynamics, making tailored checklists with ergonomics perspective, etc. were taught to the participants. To ensure the efficiency of training programs in increasing the ergonomics knowledge of steering committee members, pre-tests and post-tests were taken for every workshop through which all the steering committee members successfully passed the courses. In the next stage, action groups were purposefully formed consisting of at least one representative from steering committee members, whose main aim was transferring the acquired ergonomics knowledge to action groups so that active training centers in different targeted units could be established. As the most acquainted staff with the operational processes, i.e., shop floor workers were also invited to participate in action groups, technical assessments including tasks analyses were precisely conducted in all workstations of the targeted units across the industry.

Accordingly, several tailored checklists were provided for recognizing ergonomic problems therein. The checklists also utilized to make a list of priorities for promoting working conditions, through which the ergonomics awareness of both inspectors and action groups could increase. To develop the checklists, general working conditions, workstation design or redesign, individuals' postures, manual material handling and hand tools were considered as ergonomics issues. In the development process of the checklists, different references, including ILO checkpoints and the Finnish institute of occupational health were considered, together with general knowledge concerning main ergonomics risk factors in targeted units (Laitinen et al. 2000; Choobineh et al. 2004b). Then, a list was assigned containing more than one hundred ergonomic problems in the industry all of which were prioritized by steering committee based on the severity of the ergonomic problem.

After initial prioritization of the ergonomic problems, the steering committee members developed relevant ergonomic solutions with the maximum usability for each item which ultimately resulted in development of strategic action plans with an estimated required time of $2-3$ years. Then, the approved interventions were implemented practically in selected units (Choobineh et al. 2021) (Table 1).

\section{Phase 2: assessing the effectiveness of participatory ergonomic intervention program}

In this phase, the methodology was focused on assessing the effectiveness of the EIP. Figure 1 summarizes the study steps from the beginning to the end. 
Table1 Examples of ergonomic challenges in targeted units and implemented solutions (Choobineh et al. 2021)

Ergonomic challenges in the workplace

1 Manual material handling (MMH) of trays, grill skewers, etc. in "general service and welfare" unit (i.e., restaurants)

2 Repetitive motions, awkward postures, contact with sharp edges in "general service and welfare" unit (i.e., restaurants)

3 Inappropriate workstation in spare-part preparation warehouse site in "central workshop"

4 Manual transferring ladles in the "steel production unit" (refractory workshop)

5 Low accessibility to operation point and awkward postures adopted (e.g., extended trunk and toes) in transportation unit

6 Manual handling of loops by workers contributing to injury hazards and awkward postures in "cold rolling" unit

7 Manual lifting/carrying of heavy objects by workers on repair platform in "iron production" unit

8 Improper VDT workstations in "information technology" unit
Corrective measures

Providing pallet jacks, jacked carts, and trolleys

Providing tray washing machines for cooking centers

Affording specialized tables with different heights for placing different-size parts

Providing forklifts for moving and manipulating full ladles

Designing a portable platform to access the inner part of the compressor module when repairing

Designing wheeled carts to carry loops

Providing tools, e.g., tailored carts to carry heavy loads on repair platform

Redesigning VDT workstations
Fig. 1 Steps of EIP and assessment of its effectiveness

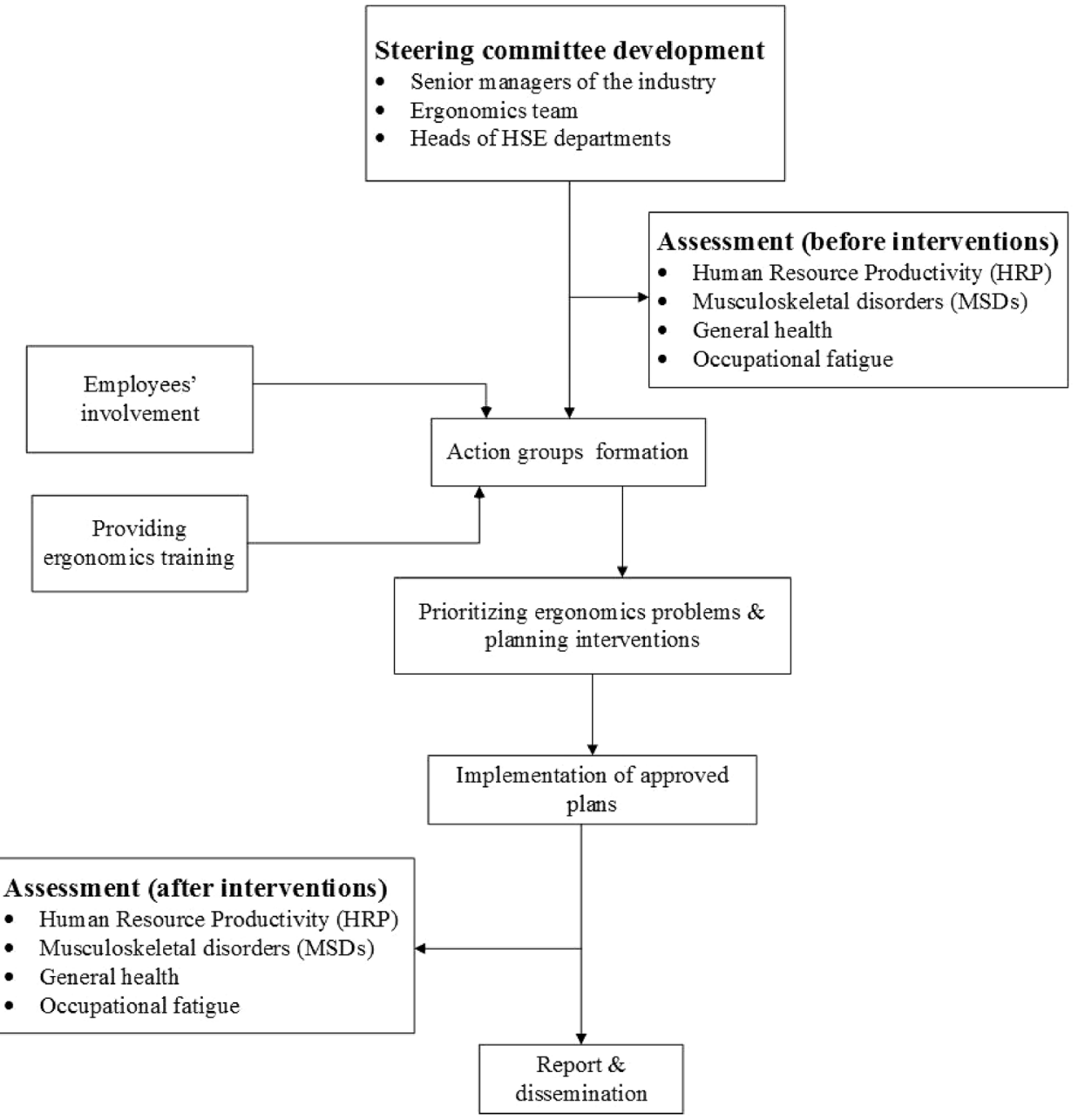




\section{Participants}

The total number of personnel working in the studied complex was over 14,000 , of which 2348 shop-floor workers were employees were enrolled and partook in the intervention program. The participants were recruited based on the cluster-randomized method from different units of the steel industry. Due to the large size of population and variety of units in the studied complex, the population was divided by targeted units into clusters. A list of all clusters was made and investigators draw a random number of clusters to be included. Then, all individuals within these clusters were listed and another turn of random selection was run to get a final random sample, exactly as simple random sampling. The sample size of participated workers by each selected unit was calculated through Cochran formula before and after the EIP (Table 2).

In this cross-sectional study, the inclusion criteria were the workers' acceptance to participate to the study as well as full-time working in the targeted units of the industry with at least 1 year job experience. The past medical history of workers was considered and those workers with previous non-work related musculoskeletal disorders or accidents in their health history records and any other physical or mental health problems which might have impact on health, i.e., musculoskeletal system or psychological state (except their work) were excluded. In addition, those participants reluctant to continue partaking in this study were excluded without any restriction.

To assess the effectiveness of the program, HRP, MSDs, general health and occupational fatigue were assessed before and after the interventions among the participants. In this regard, 430 employees of the targeted units were selected to participate in the study. In the next stage, after a 2 year

Table 2 Sample size of workers participated in the study before and after the EIP by targeted unit

\begin{tabular}{|c|c|c|c|c|}
\hline & \multirow[t]{2}{*}{ The targeted units } & \multirow[t]{2}{*}{ Size of cluster } & \multicolumn{2}{|l|}{ Sample size } \\
\hline & & & Before EIP & After EIP \\
\hline 1 & $\begin{array}{l}\text { General service and } \\
\text { welfare }\end{array}$ & 484 & 87 & 65 \\
\hline 2 & Central workshop & 332 & 65 & 48 \\
\hline 3 & Steel production & 350 & 68 & 41 \\
\hline 4 & Cold rolling & 593 & 109 & 73 \\
\hline 5 & Transportation & 146 & 21 & 13 \\
\hline 6 & Iron production & 260 & 43 & 32 \\
\hline 7 & $\begin{array}{l}\text { Human resources (HR) } \\
\text { education and devel- } \\
\text { opment }\end{array}$ & 55 & 11 & 8 \\
\hline \multirow[t]{2}{*}{8} & $\begin{array}{l}\text { Information technology } \\
\text { (IT) }\end{array}$ & 128 & 26 & 15 \\
\hline & Total & 2348 & 430 & 295 \\
\hline
\end{tabular}

intervention, 295 employees of the studied units were participated in fulfilling the questionnaires. Apart from the restrictions made by COVID-19 outbreak, which led to decrease the number of participants after EIP, there were no any important organizational changes during the 2 year study. It should be noted that prior to fulfilling the questionnaires, either paper version (before the EIP) or online format (after the EIP), the objectives and the protocol of the study were explained to the participants to whom the confidentiality of the questionnaire's data were assured.

\section{Data acquisition tools}

Six self-administered questionnaires including socio-demographic questionnaire, HRP, NMQ, GHQ-28, SOFI-20 and OFER-15 were used in the study before and after EIP as pretest and post-test evaluation. The questionnaires were completed by the participants in paper version before the EIP, while after that they were fulfilled online due to COVID-19 outbreak restrictions. The questionnaires used before and after the EIP were identical in all aspects including the quality of responses and were distributed, fulfilled and analyzed independently (Braekman et al. 2018).

\section{Socio-demographic questionnaire}

This questionnaire contained necessary information about relevant socio-demographic characteristics of the participants including age, gender, height and weight, marital status, level of education and job tenure.

\section{Human resources productivity (HRP) questionnaire}

In the current study, HRP Questionnaire, abstracted from Achio model (ACHIEVE) and developed by Hershey and Goldsmith in 1980, was used (Hersey and Goldsmith 1980). This questionnaire contained 26 questions which examined 7 dimensions of HRP defined in ACHIEVE model. The 7 dimensions included ability, perception and cognition, motivation, organizational support, feedback, validity, and compatibility. The five-point Likert scale was used for the questionnaire as the scoring system (very low $=1$, low $=2$, medium $=3$, high $=4$, very high $=5$ ). The validity and reliability of the Persian version of this questionnaire was evaluated and confirmed in a study by Nasiripour et al. (2009).

\section{Nordic musculoskeletal questionnaire (NMQ)}

The NMQ is used to survey the prevalence of MSDs. The NMQ was developed and administered by the Korhan Institute of Occupational Health to determine the prevalence of WMSDs (Kuorinka et al. 1987). Based on this questionnaire, the respondents were asked to specify 
whether they had experienced any discomfort/pain in different body regions during the last 12 months and also during last week with the answers per region being evaluated by a dichotomous scale (yes or no). In the current study, only the discomfort/pain in different regions of the body during the last 12 months was considered among the participants. The validity and reliability of the Persian version of this questionnaire was evaluated and confirmed by (Choobineh et al. (2004a).

\section{8-Item general health questionnaire (GHQ-28)}

To investigate the effect of the ergonomics interventions on overall well-being of the participants, the GHQ-28 was used. The GHQ-28 asks participants to report the total quality of their health over the past few weeks through which certain behavioral items with a 4-point scale including "not at all", "no more than usual", "rather more than usual" and "much more than usual" are assessed. The scoring system of this questionnaire is based on the Likert scale from 0 to 3 . Indeed, each individual's total score can vary from 0 to 84 . Higher GHQ-28 scores indicate higher levels of distress. It is suggested that participants with total scores of 23 or below should be classified as non-psychiatric, while participants with scores of 24 or more may be classified as psychiatric (Taghavi 2002). The validity and reliability of the Persian version of this questionnaire was investigated and confirmed by (Javanmard and Mamaghani (2013).

\section{Swedish occupational fatigue inventory (SOFI-20)}

In this study, the SOFI-20 questionnaire was used to assess the physical, mental and some other aspects of work related occupational fatigue. This questionnaire is a multidimensional tool developed by Ahsberg et al. (1997) to assess the quality and severity of perceived occupational fatigue (Åhsberg et al. 1997). The 20-item version of this questionnaire consists of five dimensions: "Physical exertion", "Physical discomfort", "Lack of motivation", "Sleepiness" and "Lack of energy" each of which is measured with four items using 11-point Likert scale from zero (not at all) to 10 (strongly agree). The dimensions of "physical exertion" and "physical discomfort" indicate physical fatigue, and the dimensions of "lack of motivation" and "sleepiness" show work-related mental fatigue. These four dimensions are called the specific dimensions of fatigue. The "lack of energy" dimension is the general dimension of fatigue that describes the qualitative resultant of physical and mental fatigue. The validity and reliability of the Persian version of this questionnaire was evaluated and confirmed by Javadpour et al. (2015).

\section{Occupational fatigue/exhaustion recovery (OFER-15) questionnaire}

In this study, OFER-15 was used to assess occupational fatigue/exhaustion recovery. This questionnaire consists of 15 questions that retrospectively examine the three dimensions of chronic fatigue, acute fatigue and inter-shift recovery, on a 7-point Likert scale, from "Zero: strongly disagree" to "6: strongly agree". Finally, comparable values are obtained for each dimension in the score range from 0 to 100. A higher score in each of these dimensions would indicate a "higher" intensity of occupational fatigue. The validity and reliability of the Persian version of this questionnaire was evaluated and confirmed in previous studies (Winwood et al. 2006; Javadpour et al. 2014).

\section{Statistical analysis}

The Shapiro-Wilk test was used to check data normality. In addition, to compare the sociodemographic data of the two independent groups (before and after the interventions), Chisquare tests (gender, marriage and education level) and independent $t$ test (age, work experience and body mass index) were used. In addition, independent $t$ test was used to compare the two study groups for the variables of HRP, general health, occupational fatigue and all their related dimensions (Grove and Cipher 2019). In addition, the non-parametric method of Mann-Whitney $U$ test was used to compare the prevalence of MSDs in body regions in the last 12 months between the two study groups as the data distribution was not normal (Upadhyay et al. 2015; Stevens et al. 2019). The Statistical Package for Scientific Science (SPSS), version 22.0 software was used for the analyses.

\section{Results}

The socio-demographic characteristics of the participants before and after ergonomic interventions are presented in Table 3.

The results of assessing the effectiveness of the EIP with a participatory approach in the studied industry are as follows:

\section{Human resources productivity (HRP)}

The results of the dimensions of HRP among the two independent groups are presented in Table 2. Independent $t$ test showed that HRP increased significantly after the interventions $(p<0.001)$ (Table 4). As it can be observed, all HRP dimensions showed an improvement after the intervention, 
Table 3 Socio-demographic characteristics of the participants

\begin{tabular}{|c|c|c|c|}
\hline Variables & $\begin{array}{l}\text { Before the } \\
\text { intervention } \\
(n=430)\end{array}$ & $\begin{array}{l}\text { After the } \\
\text { intervention } \\
(n=295)\end{array}$ & $p$ value* \\
\hline Age (years) $(\mathrm{M} \pm \mathrm{SD})$ & $38.09 \pm 7.02$ & $37.28 \pm 6.57$ & 0.335 \\
\hline $\begin{array}{c}\mathrm{BMI}\left(\mathrm{Kg} / \mathrm{m}^{2}\right) \\
(\mathrm{M} \pm \mathrm{SD})\end{array}$ & $26.37 \pm 15.7$ & $24.4 \pm 2.6$ & 0.143 \\
\hline \multirow[t]{2}{*}{$\begin{array}{l}\text { Job tenure (years) } \\
(\mathrm{M} \pm \mathrm{SD})\end{array}$} & $9.96 \pm 4.16$ & $8.84 \pm 5.54$ & 0.178 \\
\hline & & & $p$ value $* *$ \\
\hline Gender & & & 0.933 \\
\hline Male & $419(97.44)$ & $289(97.96)$ & \\
\hline Female & $11(2.56)$ & $6(2.03)$ & \\
\hline Marital status & & & 0.923 \\
\hline Married & $362(84.18)$ & $247(83.72)$ & \\
\hline Single & $68(15.82)$ & $48(16.28)$ & \\
\hline \multicolumn{4}{|l|}{ Education level } \\
\hline Primary school & $54(12.55)$ & $43(14.57)$ & 0.193 \\
\hline Diploma & $170(34.34)$ & $126(42.71)$ & \\
\hline $\mathrm{AD}$ & 45 (10.46) & $25(8.47)$ & \\
\hline $\mathrm{BSc}$ & $153(35.58)$ & $96(32.54)$ & \\
\hline (MSc) and higher & $8(1.86)$ & $5(1.69)$ & \\
\hline
\end{tabular}

$A D$ Associate's degree; $B S c$ Bachelor of science degree; $M S c$ Master of science degree

*Independent $t$ test; **Chi square test

out of which the mean scores of perception and recognition, organizational support, motivation and validity were significantly different $(p<0.05)$.

\section{Musculoskeletal disorders (MSDs)}

The results of the prevalence of MSDs in the last 12 months using the NMQ before and after the interventions are presented in Table 3. Due to the qualitative innate of the MSDs variables, Mann-Whitney $U$ test was used to compare the prevalence of MSDs in different body regions between the two study groups. The statistical analyses showed that the prevalence of disorders was decreased in the last 12 months after the interventions (Table 5).

\section{General health}

Table 6 shows the results of the GHQ before and after the interventions. Statistical analyses using independent $t$ test showed a significant difference of the mean general health between the two groups $(p<0.001)$. Overall, these findings indicate that the mean of overall general health and all its related dimensions (i.e., somatic symptoms, anxiety, social dysfunction and depression) were decreased in the postintervention group. Considering the fact that reducing the mean of dimension scores in this questionnaire means better situation, it can be inferred that the dimensions of the GHQ have significantly improved in the post-intervention group.

\section{Occupational fatigue}

Occupational fatigue was compared between the two study groups (Table 7). Independent $t$ test showed that there was a significant difference in total occupational fatigue between the two groups $(p=0.004)$, so that it was decreased and improved after the interventions. The mean scores of the relevant dimensions (lack of energy, physical discomfort and sleepiness) also was decreased significantly after the interventions $(p<0.05)$.

\section{Discussion}

The aim of this study was to assess the effectiveness of an EIP on HRP, MSDs, general health and occupational fatigue in a steel industry. The findings of this study showed the positive effect of the program on increasing HRP and general health as well as decreasing MSDs prevalence and occupational fatigue among the employees. Although the direct positive effects of EIP on WMSDs were not clear, the shop floor workers reported fewer musculoskeletal pain
Table 4 Comparison of the mean scores of HRP among the study groups before $(n=430)$ and after the interventions $(n=295)$

\begin{tabular}{lllr}
\hline HRP & $\begin{array}{l}\text { Before intervention } \\
\text { Mean (SD) }\end{array}$ & $\begin{array}{l}\text { After intervention } \\
\text { Mean (SD) }\end{array}$ & $p$ value* $^{*}$ \\
\hline Ability & $10.36(2.34)$ & $10.30(2.80)$ & 0.705 \\
Perception and cognition & $11.37(2.80)$ & $11.89(3.33)$ & 0.024 \\
Organizational support & $11.26(3.17)$ & $11.99(3.83)$ & 0.005 \\
Motivation & $8.99(3.32)$ & $10.23(4.13)$ & $<0.001$ \\
Feedback & $12.27(2.97)$ & $12.63(3.91)$ & 0.166 \\
Validity & $11.08(3.59)$ & $11.85(4.03)$ & 0.009 \\
Compatibility & $10.23(2.76)$ & $9.83(3.19)$ & 0.072 \\
Total HRP & $75.18(15.64)$ & $80.71(17.56)$ & $<0.001$ \\
\hline
\end{tabular}

*Independent $t$ test 
Table 5 Comparison of the prevalence of MSDs before $(n=430)$ and after the interventions $(n=295)$

\begin{tabular}{lllr}
\hline Body regions & $\begin{array}{l}\text { Before } \\
\text { intervention } \\
\text { number }(\%)\end{array}$ & $\begin{array}{l}\text { After } \\
\text { intervention } \\
\text { number }(\%)\end{array}$ & $p$ value* \\
\hline Neck & $170(39)$ & $46(18.6)$ & 0.001 \\
Shoulders & $134(30.7)$ & $45(18.2)$ & 0.105 \\
Elbows & $77(17.7)$ & $15(6.1)$ & 0.002 \\
wrist/hands & $107(24.5)$ & $27(10.9)$ & 0.006 \\
Upper back & $137(31.4)$ & $27(10.9)$ & $<0.001$ \\
Lower back & $203(46.6)$ & $58(23.5)$ & 0.001 \\
Thighs & $58(13.3)$ & $23(9.3)$ & 0.001 \\
Knees & $142(32.6)$ & $46(18.6)$ & 0.008 \\
ankle/foot & $138(31.7)$ & $41(16.6)$ & 0.020 \\
\hline
\end{tabular}

Mann-Whitney $U$ test

and fatigue after the EIP. The integration of training workshops, participatory approach, and workstation redesign could considerably boost the effectiveness of any intervention program. Permanent participatory efforts for solving ergonomic problems also require basic knowledge of ergonomics accompanied with remarkable expertise in teamwork as action groups.

Previous studies have also confirmed the positive effect of EIPs on employees' health and system's efficiency. Therefore, it seems that the simultaneous use of participatory ergonomics approach with long-term follow-up and betterment of working conditions can improve the chance of accepting ergonomics principles and the success of EIPs in the workplace (Heidarimoghadam et al. 2020). Hermawati et al. in a review study assigned three approaches through which ergonomists could partake in betterment of working conditions within industrial workplaces. The first of these approaches concentrates on implementing the participatory ergonomics, which enables workers to become engaged in improving their workplace by working together with the top managers of industries. The two other approaches concentrate on providing necessary grounds for persuading the production of local technology and tools for industrial workplaces, as well as the 'proper modification of ergonomics tools'. Local technology refers to as a regional production of necessary tools. In addition, the aim of implementing EIP in the workplace was considering two predicaments including the need to implement the participatory ergonomics in the workplace and decrease the commonly implemented top-bottom approach (Lawson et al. 2021), both of which could be tackled in the current study.

\section{Human resource productivity (HRP)}

Significant differences were found between the scores of HRP before and after the ergonomics interventions so that after ergonomic interventions, HRP improved. Many studies, such as the study of Lawson et al. have confirmed that the enthusiastic participation of the management team and shop floor workers could mostly make them feel decision making responsibility and a sense of usefulness leading to increasing HRP (Lawson et al. 2021; Pascual et al. 2021). In addition, Martimo et al. showed that reducing physical
Table 6 Comparison of mean scores of GHQ dimensions among the study groups before $(n=430)$ and after the intervention $(n=295)$

\begin{tabular}{llll}
\hline General health dimensions & $\begin{array}{l}\text { Before intervention } \\
\text { Mean (SD) }\end{array}$ & $\begin{array}{l}\text { After intervention } \\
\text { Mean (SD) }\end{array}$ & $p$ value* \\
\hline Somatic symptoms & $4.81(2.51)$ & $3.54(3.20)$ & $<0.001$ \\
Anxiety/insomnia & $5.12(3.38)$ & $2.95(3.56)$ & $<0.001$ \\
Social dysfunction & $12.65(3.76)$ & $10.04(6.80)$ & $<0.001$ \\
Severe depression & $1.90(2.63)$ & $1.26(2.81)$ & $<0.001$ \\
Total general health & $24.48(8.00)$ & $18.16(11.64)$ & $<0.001$ \\
\hline
\end{tabular}

*Independent $t$ test

\begin{tabular}{llll}
\hline Occupational fatigue dimensions & $\begin{array}{l}\text { Before the interventions } \\
\text { Mean (SD) }\end{array}$ & $\begin{array}{l}\text { After the interventions } \\
\text { Mean (SD) }\end{array}$ & $p$ value* \\
\hline Lack of energy & $14.32(9.96)$ & $10.65(10.53)$ & 0.001 \\
Physical exertion & $9.36(7.97)$ & $7.65(9.07)$ & 0.065 \\
Physical discomfort & $11.40(9.41)$ & $8.65(9.62)$ & 0.009 \\
Lack of motivation & $9.68(8.12)$ & $7.99(8.19)$ & 0.061 \\
Sleepiness & $11.26(9.63)$ & $7.92(9.01)$ & 0.001 \\
Total occupational fatigue & $54.79(38.62)$ & $45.70(41.95)$ & 0.004 \\
\hline
\end{tabular}

*Independent $t$ test
Table 7 Comparison of the mean scores of dimensions of SOFI among the participants before $(n=430)$ and after the interventions $(n=295)$ 
workload caused the productivity of workers with a history of upper extremities diseases to be improved. This improvement could be due to the workstation redesigns and correcting employees' inappropriate work styles (Martimo et al. 2010; Sohrabi and Babamiri 2021). The results of the study of Faraji Kojerdi et al. also showed the positive effects of the EIP with a participatory approach on improving the workplace condition (Kujerdi et al. 2021).

\section{Musculoskeletal disorders (MSDs)}

According to the findings, the interventions implemented in the studied industry yielded a descending trend in the prevalence of MSDs in different body regions of the participants compared to those reported before the interventions. This decrease was statistically significant for the neck, elbows, hand/wrists, upper back, lower back/hip, knee and ankle/ feet. According to the previous studies, ergonomic corrective actions in industries, including training ergonomics principles to employees, redesigning workstations and applying the creative ideas of employees in an organization, each in turn can improve both working postures and workplace conditions (Jain et al. 2018; Colim et al. 2020; Zare et al. 2020; Jadhav and Arunachalam 2021; Kujerdi et al. 2021).

One of the barriers in implementing ergonomic interventions is insufficient intervention time and its followup process, which may affect the results (Lidegaard et al. 2018). However, it seems that with more involvement of the employees in participatory ergonomic interventions, this challenge would be partially tackled (Stevens et al. 2019). Therefore, greater participation in decision-making and a positive understanding of ergonomics in the workplace are associated with higher productivity and lower prevalence of MSDs (Lawson et al. 2021). The study of Loisel et al. also showed that participatory interventions, even in a short term (e.g., 6 months) could increase the rate of return to work of those workers with a history of sub-acute occupational low back pain due to increasing awareness of those ergonomic risk factors contributing to low back injury (Loisel et al. 2001). However, another study examining the effect of a participatory ergonomic intervention on the prevention of MSDs among kitchen workers found no evidence for the effectiveness of the intervention in preventing MSDs and reducing perceived physical workload, which could be likely due to the low participation of workers in the intervention (Haukka et al. 2008).

\section{General health}

In this study, participatory ergonomic interventions showed a positive and significant effect on general health of the participants after the interventions. In general, the previous studies confirm that some physical, mental and general health factors were associated with the prevalence of MSDs (Barzideh et al. 2014). A study conducted in an oil industry showed that low back pain was associated with symptoms of anxiety and abnormalities in social, physical and general health (Mohammadi 2020). The results of the study by Daneshmandi et al. also confirmed the positive effects of reducing MSDs on improving psychosocial factors and performance of individuals (Daneshmandi et al. 2017).

\section{Occupational fatigue}

After performing ergonomic interventions in the steel industry, occupational fatigue showed a significant decrease and fatigue exhaustion recovery was significantly improved. Based on the literature, general fatigue as a sign of decreased work performance would be mostly reduced through improving various aspects of work, such as work organization, working with the body's neutral posture in balance with the body's ability and reducing workload. These improvements can be made on the basis of participatory ergonomic interventions (Cervai and Polo 2018). In a study by Haghshenas et al. some psychosocial parameters were evaluated to measure the effectiveness of a participatory ergonomic intervention. The parallel results of this study with the results of the present study indicated that an organized participatory ergonomic intervention could positively affect perceived fatigue reduction followed by job satisfaction as a sense of usefulness. However, compared to our study, the efficiency of their intervention on perceived fatigue was less, which could be possibly due to their study follow-up time limit (Haghshenas et al. 2018). Motamedzadeh et al. examined MSDs by evaluating muscle fatigue and concluded that MSDs in the neck and shoulders were more common than other areas of the body (Motamedzade et al. 2016).

In general, the findings of the present study indicated improvement of HRP, MSDs, general health, and occupational fatigue following the implementation of the EIP and working conditions betterment. Given the sufficient duration of the intervention (more than 2 years), and considering the establishment of a localized system for improving ergonomic conditions in the steel industry, which was achieved by implementing a comprehensive participatory program, obtaining such results was expectable. Nevertheless, the present study had also some limitations.

First, although assessments indicated fewer complaints on MSDs among the workers after the EIP, WMSDs were statistically difficult to be precisely assessed as they were multifaceted and required more caution to be interpreted. Second, due to the crisis of COVID-19 outbreak, the number of individuals who filled out the questionnaires in the postintervention assessment was lower than those participating in the pre-intervention stage. However, it was statistically valid, sufficient and comparable. 


\section{Conclusion}

The findings of the current study showed that the implementation of the EIP, using participatory ergonomics, training and redesign of workstations was effective in increasing HRP and general health as well as decreasing MSDs and occupational fatigue. One of the most important factors in the success of this EIP was the involvement of all layers of the organization from the management team to the shop floor workers and the enthusiastic participation of them accompanied with the action groups of different units in providing operational and cost-effective ideas to solve ergonomic problems. Assessing the effectiveness of ergonomic interventions seems to be very useful to persuade industrial managers to incorporate ergonomic programs in policy and management planning. Implementing an EIP with a similar approach and with the simultaneous use of participatory ergonomics, training and redesign of workstations is recommended for different industries.

Acknowledgements This study was financially supported by Mobarakeh Steel Company via contract no. 48445257 and was registered at Shiraz University of Medical Sciences with reference number of $95-77-28$

\section{Declarations}

Conflict of interest The authors have no conflict of interest to declare.

\section{References}

Åhsberg E, Garnberale F, Kjellberg A (1997) Perceived quality of fatigue during different occupational tasks development of a questionnaire. Int J Ind Ergon 20(2):121-135

Amick BC III et al (2003) Effect of office ergonomics intervention on reducing musculoskeletal symptoms. Spine 28(24):2706-2711

Barzideh M, Choobineh A, Tabatabaee H (2014) Job stress dimensions and their relationship to musculoskeletal disorders in Iranian nurses. Work 47(4):423-429

Bazazan A, Dianat I, Feizollahi N, Mombeini Z, Shirazi AM, Castellucci HI (2019) Effect of a posture correction-based intervention on musculoskeletal symptoms and fatigue among control room operators. Appl Ergon 76:12-19

Bernardes JM, Ruiz-Frutos C, Moro ARP, Dias A (2021) A low-cost and efficient participatory ergonomic intervention to reduce the burden of work-related musculoskeletal disorders in an industrially developing country: an experience report. Int J Occup Saf Ergon 27(2):452-459

Bosch LM, van der Molen HF, Frings-Dresen MH (2018) Optimizing implementation of interventions in agriculture for occupational upper extremity musculoskeletal disorders: results of an expert panel. Work 61(3):413-420

Braekman E et al (2018) Measurement agreement of the selfadministered questionnaire of the Belgian health interview survey: paper-and-pencil versus web-based mode. PLoS One 13(5):e0197434
Burke MJ, Sarpy SA, Smith-Crowe K, Chan-Serafin S, Salvador RO, Islam G (2006) Relative effectiveness of worker safety and health training methods. Amer J Pub Health 96(2):315-324

Cervai S, Polo F (2018) The impact of a participatory ergonomics intervention: the value of involvement. Theor Issues Ergon Sci 19(1):55-73

Choobineh A, Lahmi M, Shahnavaz H, Khani Jazani R, Hosseini M (2004a) Musculoskeletal symptoms as related to ergonomic factors in Iranian hand-woven carpet industry and general guidelines for workstation design. Int J Occup Saf Ergon 10(2): 157-168

Choobineh A, Shahnavaz H, Lahmi M (2004b) Major health risk factors in Iranian hand-woven carpet industry. Int J Occup Saf Ergon 10(1):65-78

Choobineh A, Tabatabaee SH, Behzadi M (2009) Musculoskeletal problems among workers of an Iranian sugar-producing factory. Int J Occup Saf Ergon 15(4):419-424

Choobineh A, Motamedzade M, Kazemi M, Moghimbeigi A, Pahlavian AH (2011) The impact of ergonomics intervention on psychosocial factors and musculoskeletal symptoms among office workers. Int J Ind Ergon 41(6):671-676

Choobineh A, Soleimani E, Daneshmandi H, Mohamadbeigi A, Izadi K (2012) Prevalence of musculoskeletal disorders and posture analysis using RULA method in Shiraz general dentists in 2010. J Islam Dent Assoc Iran 24(4):310-317

Choobineh A, Daneshmandi H, Aghabeigi M, Haghayegh A (2013a) Prevalence of musculoskeletal symptoms among employees of Iranian petrochemical industries: October 2009 to December 2012. Int J Occup Environ Med (The IJOEM) 4:253-195

Choobineh A, Daneshmandi H, Asadi S, Ahmadi S (2013b) Prevalence of musculoskeletal symptoms and assessment of working conditions in an Iranian petrochemical industry. J Health Sci Surveill Syst 1(1):33-40

Choobineh A, Daneshmandi H, Fard SKSZ, Tabatabaee SH (2016) Prevalence of work-related musculoskeletal symptoms among Iranian workforce and job groups. Int J Prev Med 7(1):130-137. https://doi.org/10.4103/2008-7802.195851

Choobineh A, Shakerian M, Faraji M, Modaresifar H, Kiani J, Hatami M, Akasheh S, Rezagholian A, Kamali G (2021) A multilayered ergonomic intervention program for reducing musculoskeletal disorders in an industrial complex: a dynamic participatory approach. Int J Ind Ergon 86:103221. https://doi.org/10.1016/j.ergon.2021. 103221

Cole D, Rivilis I, Van Eerd D, Cullen K, Irvin E, Kramer D (2005) Effectiveness of participatory ergonomic interventions: a systematic review. Database of Abstracts of Reviews of Effects (DARE): Quality-assessed Reviews [Internet]

Colim A, Sousa N, Carneiro P, Costa N, Arezes P, Cardoso A (2020) Ergonomic intervention on a packing workstation with robotic aid-case study at a furniture manufacturing industry. Work 66(1):229-237

Cook C, Burgess-Limerick R (2004) The effect of forearm support on musculoskeletal discomfort during call centre work. Appl Ergon 35(4):337-342

Daneshmandi H, Choobineh A, Ghaem H, Alhamd M, Fakherpour A (2017) The effect of musculoskeletal problems on fatigue and productivity of office personnel: a cross-sectional study. J Prev Med Hyg 58(3):E252

Daneshmandi H, Choobineh A, Ghaem H, Hejazi N (2019) Proper sit-stand work schedule to reduce the negative outcomes of sedentary behavior: a randomized clinical trial. Int J Occup Saf Ergon. https://doi.org/10.1080/10803548.2019.1679972

Dohrmann SB, Leppin A (2017) Determinants of seafarers' fatigue: a systematic review and quality assessment. Int Arch Occup Environ Health 90(1):13-37 
Emmatty FJ, Panicker VV (2019) Ergonomic interventions among waste collection workers: a systematic review. Int J Ind Ergon $72: 158-172$

Ervasti J et al (2019) Long-term exposure to heavy physical work, disability pension due to musculoskeletal disorders and allcause mortality: 20-year follow-up-introducing Helsinki health study job exposure matrix. Int Arch Occup Environ Health 92(3):337-345

Gerr F, Marcus M, Monteilh C, Hannan L, Ortiz D, Kleinbaum D (2005) A randomised controlled trial of postural interventions for prevention of musculoskeletal symptoms among computer users. Occup Environ Med 62(7):478-487

Grove SK, Cipher DJ (2019) Statistics for nursing research-e-book: a workbook for evidence-based practice. Elsevier Health Sciences, Amsterdam

Haghshenas B, Habibi E, Haji Esmaeil Hajar F, Ghanbary Sartang A, van Wijk L, Khakkar S (2018) The association between musculoskeletal disorders with mental workload and occupational fatigue in the office staff of a communication service company in Tehran, Iran, in 2017. J Occup Health Epid 7(1):20-29

Hallman DM, Holtermann A, Björklund M, Gupta N, Rasmussen CDN (2019) Sick leave due to musculoskeletal pain: determinants of distinct trajectories over 1 year. Int Arch Occup Environ Health 92(8):1099-1108

Haukka E et al (2008) A randomised controlled trial on whether a participatory ergonomics intervention could prevent musculoskeletal disorders. Int J Occup Environ Med 65(12):849-856

Hayati A, Marzban A, Rahnama M (2021) Occupational safety and health in traditional date palm works. Int Arch Occup Environ Health 94:1455-1473. https://doi.org/10.1007/ s00420-021-01664-4

Haynes S, Williams K (2008) Impact of seating posture on user comfort and typing performance for people with chronic low back pain. Int J Ind Ergon 38(1):35-46

Heidarimoghadam R, Mohammadfam I, Babamiri M, Soltanian AR, Khotanlou H, Sohrabi MS (2020) What do the different ergonomic interventions accomplish in the workplace?. Int J Occup Saf Ergon, A systematic review. https://doi.org/10.1080/10803 548.2020.1811521

Hersey P, Goldsmith M (1980) A situational approach to performance planning. Int J Train Dev 34(11):38

Hosseini A, Choobineh A, Razeghi M, Pakshir HR, Ghaem H, Vojud M (2019) Ergonomic assessment of exposure to musculoskeletal disorders risk factors among dentists of Shiraz. Iran J Dent 20(1):53

Jacobo-Galicia G, Navarro-González CR, Montoya-Reyes M, Mendoza-Muñoz I, Jiménez-López E (2021) The human factor as a central element in the design of the workplace. a systematic review. In: García-Alcaraz JL, Realyvásquez-Vargas A, Z-Flores E (eds) Trends in industrial engineering applications to manufacturing process. Springer, Cham. https://doi.org/10.1007/9783-030-71579-3_19

Jacobs RL (2002) Institutionalizing organizational change through cascade training. J Eur Ind Train 26(2):177-182. https://doi.org/10. 1108/03090590210422058

Jadhav GS, Arunachalam M (2021) Musculoskeletal problems of hand-sewn crafted footwear manufacturing artisans in Kolhapur, India. Int Arch Occup Environ Health. https://doi.org/10.1007/ s00420-021-01734-7

Jain R, Sain MK, Meena ML, Dangayach GS, Bhardwaj AK (2018) Non-powered hand tool improvement research for prevention of work-related problems: a review. Int J Occup Saf Ergon 24(3):347-357

Javadpour F, Keshavarzi S, Choobineh A, Aghabaigi M (2014) Validity and reliability of occupational fatigue/exhaustion recovery scale
(OFER-15) among Iranian working population. Iran Occup Health 11(6)

Javadpour F, Keshavarzi S, Choobineh A, Aghabaigi M (2015) Validity and reliability of the Swedish occupational fatigue inventory (SOFI-20) among Iranian working population. Iran J Ergon 3(1):50-58

Javanmard GH, Mamaghani J (2013) Standardization of GHQ-28 inventory on the students of Azerbaijan province of Iran. Procedia Soc Behav Sci 84:47-52

Kujerdi MF, Mokarami H, Keshtkar V, Ziaei M, Petramfar P, Choobineh A (2021) Improving working conditions in an Iranian hospital: a participatory ergonomics approach. Int J Occup Saf Ergon 1-7

Kuorinka I et al (1987) Standardised Nordic questionnaires for the analysis of musculoskeletal symptoms. Appl Ergon 18(3):233-237

Laitinen H, Rasa P, Lankinen T (2000) ELMERI: a workplace safety and health observation method. Finnish Institute of Occupational Health, Helsinki

Lawson G, Hermawati S, Ryan B (2021) Participatory ergonomics in industrially developing countries: a literature review. Int J Mech Eng 2(1):53-59

Lidegaard M, Søgaard K, Krustrup P, Holtermann A, Korshøj M (2018) Effects of 12 months aerobic exercise intervention on work ability, need for recovery, productivity and rating of exertion among cleaners: a worksite RCT. Int Arch Occup Environ Health 91(2):225-235

Loisel P, Gosselin L, Durand P, Lemaire J, Poitras S, Abenhaim L (2001) Implementation of a participatory ergonomics program in the rehabilitation of workers suffering from subacute back pain. Appl Ergon 32(1):53-60

Martimo K-P, Shiri R, Miranda H, Ketola R, Varonen H, ViikariJuntura E (2010) Effectiveness of an ergonomic intervention on the productivity of workers with upper-extremity disordersa randomized controlled trial. Scand J Work Environ Health $36(1): 25-33$

Mohammadi G (2020) Association between prevalence of self-reported musculoskeletal disorders and general health among Iranian oil refinery workers. J Musculoskelet Res 23(01):2050002

Momeni Z, Choobineh A, Razeghi M, Ghaem H, Azadian F, Daneshmandi H (2020) Work-related musculoskeletal symptoms among agricultural workers: a cross-sectional study in Iran. J Agromedicine 25(3): $1-10$

Motamedzade M, Shahnavaz H, Kazemnejad A, Azar A, Karimi H (2003) The impact of participatory ergonomics on working conditions, quality, and productivity. Int J Occup Saf Ergon 9(2):135-147

Motamedzade M, Saedpanah K, Salimi K, Eskandari T (2016) Risk assessment of musculoskeletal disorders by muscle fatigue assessment method and implementation of an ergonomic intervention in assembly industry. J Occup Hyg Eng 3(1):33-40

Nasiripour A, Raeisi P, Hedayati S (2009) The relationship between organizational cultures and employees productivity. J Health Adm 12(35):17-24

Neshastegar F, Halvani G, Choobineh A, AhmadiyeYazdi M (2019) Prevalence of musculoskeletal disorders and determination of associated risk factors in female workers in clothing manufacturing workshops of Yazd city. Occup Med 11(2)

Oakman J, de Wind A, van den Heuvel SG, van der Beek AJ (2017) Work characteristics predict the development of multi-site musculoskeletal pain. Int Arch Occup Environ Health 90(7):653-661

Onishi T, Kurimoto S, Suzuki M, Imaeda T, Hirata H (2014) Workrelated musculoskeletal disorders in the upper extremity among the staff of a Japanese university hospital. Int Arch Occup Environ Health 87(5):547-555 
Pascual AI et al (2021) Multi-objective optimization of ergonomics and productivity by using an optimization framework. Congress of the International Ergonomics Association. Springer, pp 374-378

Pope-Ford R, Pope-Ozimba J (2020) Musculoskeletal disorders and emergent themes of psychosocial factors and their impact on health in dentistry. Work 65(3):563-571

Rasmussen CDN, Højberg H, Bengtsen E, Jørgensen MB (2018) Identifying knowledge gaps between practice and research for implementation components of sustainable interventions to improve the working environment-a rapid review. Appl Ergon 67:178-192

Shahnavaz H (1987) Workplace injuries in the developing countries. Ergonomics 30(2):397-404

Sohrabi MS, Babamiri M (2021) Effectiveness of an ergonomics training program on musculoskeletal disorders, job stress, quality of work-life and productivity in office workers: a quasi-randomized control trial study. Int J Occup Saf Ergon. https://doi.org/10.1080/ 10803548.2021.1918930

Stevens ML et al (2019) Mechanisms for reducing low back pain: a mediation analysis of a multifaceted intervention in workers in elderly care. Int Arch Occup Environ Health 92(1):49-58

Taghavi S (2002) Validity and reliability of the general health questionnaire (ghq-28) in college students of Shiraz University. J Psychol 5(4):381-398

Tajvar A et al (2021) Common errors in selecting and implementing pen-paper observational methods by Iranian practitioners for assessing work-related musculoskeletal disorders risk: a systematic review. Int J Occup Saf Ergon. https://doi.org/10.1080/10803 548.2021 .1905993

Tompa E et al (2021) Economic burden of work injuries and diseases: a framework and application in five European Union countries. BMC Public Health 21(1):1-10

Upadhyay DK, Ibrahim MIM, Mishra P, Alurkar VM (2015) A non-clinical randomised controlled trial to assess the impact of pharmaceutical care intervention on satisfaction level of newly diagnosed diabetes mellitus patients in a tertiary care teaching hospital in Nepal. BMC Health Serv Res 15(1):1-10

Van Eerd D et al (2010) Process and implementation of participatory ergonomic interventions: a systematic review. Ergonomics 53(10):1153-1166

Van Eerd D et al (2016) Dissemination and use of a participatory ergonomics guide for workplaces. Ergonomics 59(6):851-858

Wilson JR, Haines HM (1998) Participatory design in the organisational context. Global ergonomics. Elsevier, Amsterdam, pp $11-19$

Winwood PC, Lushington K, Winefield AH (2006) Further development and validation of the occupational fatigue exhaustion recovery (OFER) scale. Int J Occup Environ Med 48(4):381-389

Yancheshmeh FA, Mousavizadegan SH, Amini A, Smith AP, Kazemi R (2020) Poor sleep quality, long working hours and fatigue in coastal areas: a dangerous combination of silent risk factors for deck officers on oil tankers. Int Marit Health 71(4):237-248

Zare M, Black N, Sagot J-C, Hunault G, Roquelaure Y (2020) Ergonomics interventions to reduce musculoskeletal risk factors in a truck manufacturing plant. Int J Ind Ergon 75:102896

Ziaei M, Choobineh A, Abdoli-Eramaki M, Ghaem H (2018) Individual, physical, and organizational risk factors for musculoskeletal disorders among municipality solid waste collectors in Shiraz. Iran Ind Health 56(4):308-319. https://doi.org/10.2486/indhealth. 2018-0011

Ziaei M, Choobineh A, Ghaem H, Abdoli-Eramaki M (2021) Evaluation of a passive low-back support exoskeleton (Ergo-Vest) for manual waste collection. Ergonomics 64(10):1255-1270

Publisher's Note Springer Nature remains neutral with regard to jurisdictional claims in published maps and institutional affiliations. 